\title{
The Viscoelasticity Model of Corn Straw under the Different Moisture Contents
}

\author{
Sun Zhong-Zhen, ${ }^{1}$ Jiang Huan-Xin,, Cai He-Ping, ${ }^{1}$ Yu Qiu-Sheng, ${ }^{2}$ Lu Li-Xin, ${ }^{1}$ \\ Wang Li, ${ }^{2}$ and Cai Guo-Lin ${ }^{2}$ \\ ${ }^{1}$ Department of Packaging Engineering, Jiangnan University, Wuxi 214122, China \\ ${ }^{2}$ Key Engineering Laboratory for Cereal Fermentation Technology, Jiangnan University, Wuxi 214122, China
}

Correspondence should be addressed to Jiang Huan-Xin; jhx05@263.net and Lu Li-Xin; lulx@jiangnan.edu.cn

Received 4 May 2013; Accepted 6 June 2013

Academic Editor: Jun Wang

Copyright (c) 2013 Sun Zhong-Zhen et al. This is an open access article distributed under the Creative Commons Attribution License, which permits unrestricted use, distribution, and reproduction in any medium, provided the original work is properly cited.

Viscoelastic model of corn straw, based on different moisture contents, is set up to characterise the deformation through three-point bending test. The model contains a linear elastic element, a damping element, and a nonlinear elastic element. The parameters of the model are determined according to the features of three-point bending test curve and characteristic of the model. The relationships between mechanical properties, energy absorption behavior of corn stalk, and moisture content have been, respectively, analysed. And regression analysis and curve fitting have been conducted based on various parameters and moisture contents with Matlab. These parameters provide the basis for straw crushing equipment design.

\section{Introduction}

The production of corn stalk is $2000-250$ billion kilograms in China, which contains rich nutrients. However, most of them are abandoned or burned $[1,2]$. Related studies have shown that it can be rubbed into $20-40 \mathrm{~mm}$ of forage grass as pig feed after fermentation [3]. Cutting force-displacement characteristics of corn straw varied with orientation and energy used in cutting stalk were also studied [4]. The stems connection force of corn straw, tensile properties of leaf sheath, and the impact resistant properties of the stem and leaf sheath are tested by Gao Mengxiang. The influences of position of leaf sheath, moisture content, and diameter of corn straw on mechanical properties have been studied, respectively [5]. Zhihua et al. have established mechanics model of crop stalks and given the expression of the critical force by using the theory and methods of mechanics [6]. The compression, tensile, and bending tests on barley, wheat, and corn stalks have been made by Wright et al. And they got models and methods to distinguish different varieties of straw based on biomechanics characteristics [7]. Ruxin et al. studied the rheological behavior of chopped corn stalks when on the process of roll pressure. Sticky elastic parameters of the burgers model are established through linear viscoelastic theory [8]. Pena et al. studied the mechanical behavior of thermomechanical corn stalk fibers in high-density polyethylene composites [9].

Although the mechanical performance study of corn straw has a long history, the object of study and the mechanical properties of corn straw are scattered. In this paper, three-point bending test has been done on different moisture contents of corn straw. Tests show that the result of three-point bending test is less discrete than tension and compression test. Based on the different moisture contents, the stress-strain performance of the corn stalk is studied, and viscoelastic model is established, and finally we get the constitutive equation.

\section{Materials and Methods}

2.1. Test Materials. The corn stalks tested are all produced in Damiao town, Zhaoyang city, Liaoning province. And they are all the same varieties. There are many nodes for the corn stalk. Otherwise, the thickness of the stalk is different according to the different position of the leaf sheath. This test studies the central position of the stalks, whose diameters are 


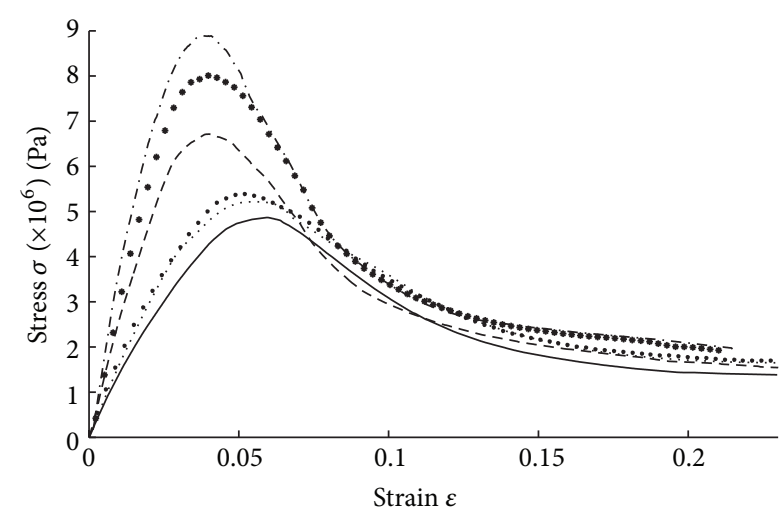

$\begin{array}{cccc} & \text { Moisture content } 0.9 & --- & \text { Moisture content } 0.4 \\ \cdots & \text { Moisture content } 0.7 & * & \text { Moisture content } 0.2 \\ \text {. } & \text { Moisture content } 0.6 & - & \text { Moisture content } 0.1\end{array}$

FIGURE 1: Stress-strain curve of corn straw in different moisture contents.

all about $20 \mathrm{~mm}$. Take 20 samples with $200 \mathrm{~mm}$ in length, and each corn stalk has two nodes and distributed symmetrically.

2.2. Test Method. Depending on the different moisture contents, number 30 corn stalks with A1-A5, B1-B5, C1-C5, D1D5, E1-E5, and F1-F5. Firstly, put them in an oven at $105^{\circ} \mathrm{C}$ for drying [10], weighing several samples every one hour, until the quality difference is less than $0.005 \mathrm{~g}$, that is, when we consider them to be completely dry, then record the quality of each sample. Secondly, take all of them into the water-bath at $30^{\circ} \mathrm{C}$ for 12 hours, which is to ensure that the moisture content is over $100 \%$ and distributed evenly. Lastly, put them in the oven again for dehydration treatment and take down each sample's quality at any time, to ensure that the moisture contents are $90 \%, 70 \%, 60 \%, 40 \%, 30 \%$, and $10 \%$ when dried to the desired quality, and then do three-point bending test. To guarantee internal water of corn stalks distributed evenly, set a lower temperature $\left(40^{\circ} \mathrm{C}\right)$ in the second oven processing, remove them from the oven in advance, and then place them in the air to reach the desired moisture content.

2.3. Test Instrument. Three-point bending experiment was conducted on the RXPlus Universal electronic testing machine made in company Lloyd in Britain, and the accuracy is $0.5 \%$. And span is $150 \mathrm{~mm}$. The force on the straw sample was applied at the deformation rate of $60 \mathrm{~mm} / \mathrm{min}$. Experiments were conducted in packaging products quality supervision and inspection center of China.

2.4. Results and Discussion. After three-point bending experiment, it showed that the stress-strain curve was similar in characteristics, and the discreteness is acceptable. Average processing was conducted for each group of data through Matlab, and curves in different moisture contents are shown (Figure 1).

The material behaves initially as a linear body and then as a viscoelastic body At the linear elastic stage, the elastic modulus decreases with the increase of moisture content
TABLE 1: Modulus of elasticity and elastic range.

\begin{tabular}{lcccccc}
\hline & $90 \%$ & $70 \%$ & $60 \%$ & $40 \%$ & $20 \%$ & $10 \%$ \\
\hline Elastic & 0.0005 & 0.0005 & 0.0005 & 0.0005 & 0.0005 & 0.0005 \\
range & 0.006 & 0.0127 & 0.0149 & 0.0168 & 0.0103 & 0.0169 \\
$\begin{array}{l}\text { Modulus of } \\
\text { elasticity E }\end{array}$ & 147.29 & 155.91 & 158.44 & 240.63 & 291.02 & 339.35 \\
\hline
\end{tabular}

TABLE 2: Parameters of model in different moisture contents.

\begin{tabular}{|c|c|c|c|c|c|}
\hline $90 \%$ & $70 \%$ & $60 \%$ & $40 \%$ & $20 \%$ & $10 \%$ \\
\hline$m 562.76$ & 3587.85 & 3332.54 & 19317.11 & 20276.59 & 92780.03 \\
\hline$n-1421.70$ & -2029.77 & -2572.36 & -5804.47 & -6684.35 & -10953.94 \\
\hline
\end{tabular}

gradually. At the viscoelastic stage, with the increase of moisture content of corn straw, strain corresponding to the yield stress also gradually increases. After the yield stress, the characteristics have no obvious correlation to the moisture content.

\section{The Viscoelastic Mechanical Model and Its Parameters}

3.1. The Viscoelastic Mechanical Model. Corn straw is viscoelastic material, and its mechanical characteristics differ with the state (moisture content, density, varieties, etc.) changing. From Figure 1, the characteristics have no obvious correlation to the moisture content after yield stress. Viscoelastic mode is used to simulate to maximum yield point. According to the test of the initial elastic phase and the viscoelastic phase, the form of three components of solid model is changed. The model includes a linear elastic element $\sigma_{e 1}$, a nonlinear elastic element $\sigma_{e 2}$, and a viscous component $\eta$. The viscous element and nonlinear elastic element connect in parallel and then connect with linear elastic components in series.

Curve equation at the linear elastic stage is

$$
\sigma_{e 1}=E \cdot \varepsilon_{1}
$$

$E$ is the line elastic element to the modulus of elasticity; $\varepsilon_{1}$ is the strain of linear elastic stage.

Curve equation at the viscoelastic stage is

$$
\begin{gathered}
\sigma_{e 2}=m \cdot \varepsilon_{2}^{3}+n \cdot \varepsilon_{2}^{2}+E \cdot \varepsilon_{2}+\eta \cdot \varepsilon_{2}^{\cdot}, \\
\sigma_{p}=\eta \cdot \dot{\varepsilon_{2}} .
\end{gathered}
$$

$m$ and $n$ are the material constants of nonlinear component; and the value are shown in Table 2 and parameter $E$ is shown in Table $1, \eta$ is the viscosity coefficient; $\varepsilon_{2}$ is the strain of linear elastic stage; point $p$ is the end of the elastic stage; $\sigma_{p}$ and $\varepsilon_{p}$ are the stress and strain, respectively.

At the beginning of the compression deformation, compression stress is small, due to the viscous damping. When compression stress is smaller than the viscous damping, all elastic stresses are shared by linear elastic element $\sigma_{e 1}$. The corn straw is linear elastic deformation, and the deformation 


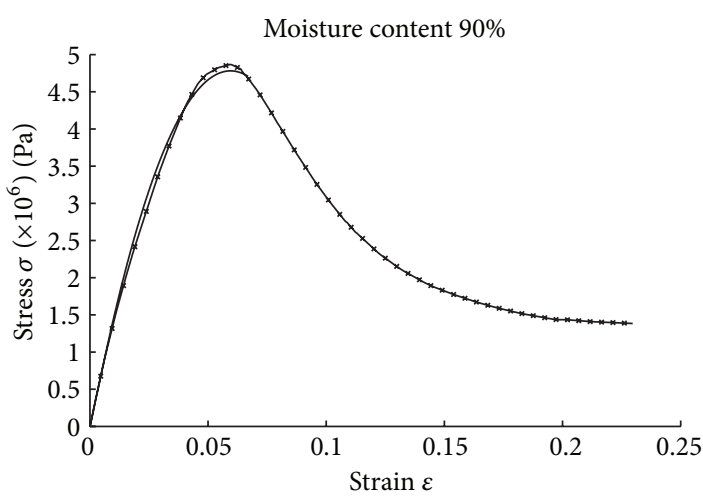

(a)

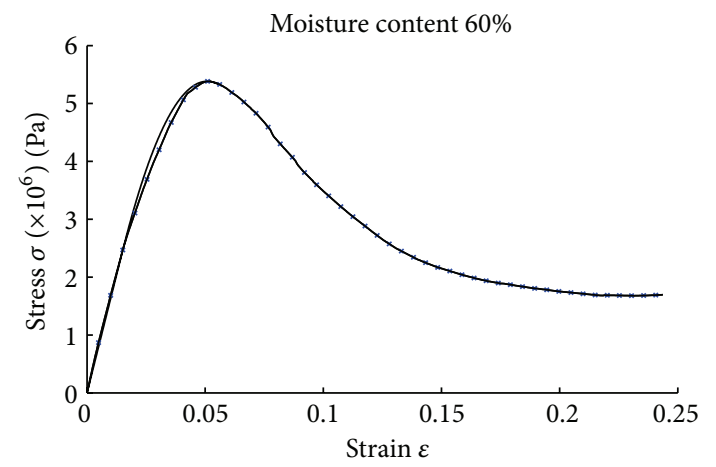

(c)

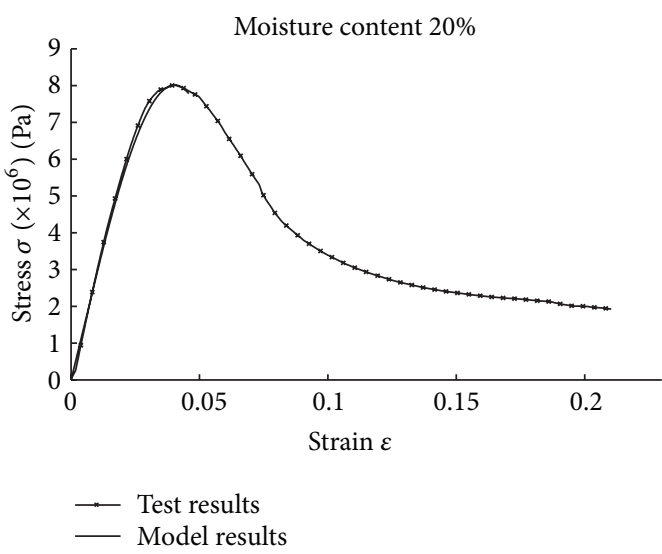

(e)

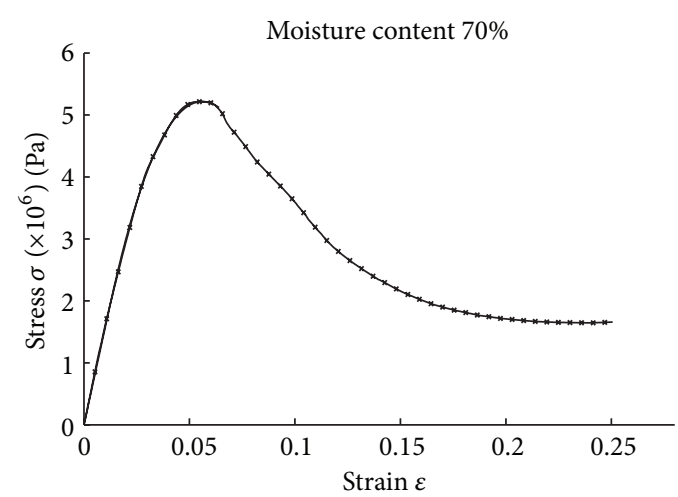

(b)

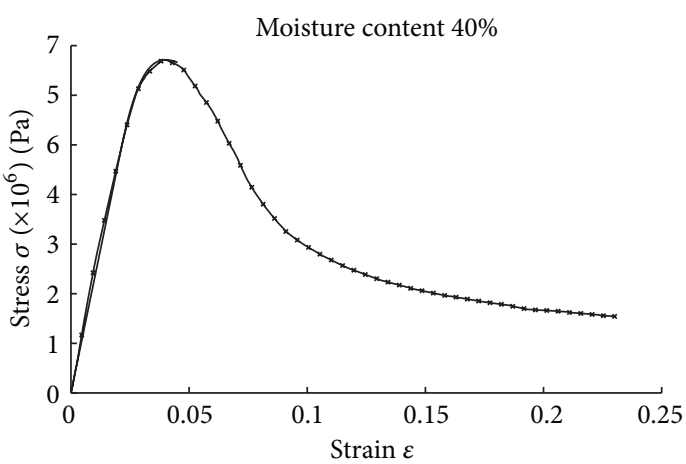

(d)

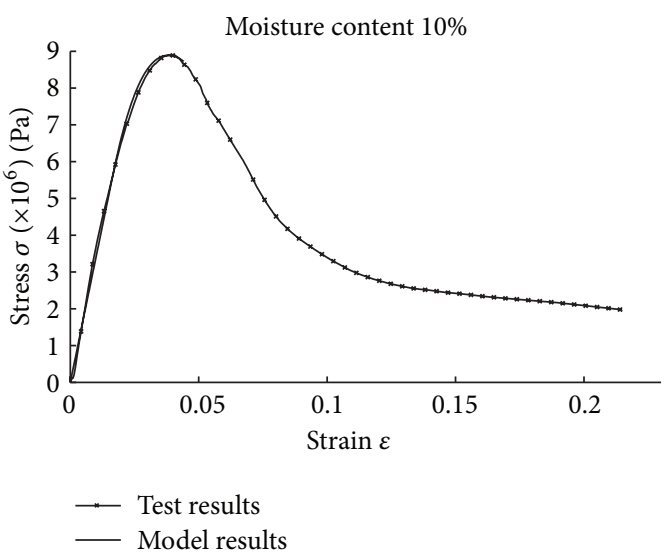

(f)

FIGURE 2: Experiment and theory simulation curves of stress-strain.

equations can be expressed as shown in the following equation:

$$
\sigma=E \cdot \varepsilon
$$

With the increase of compression deformation, $\sigma>\sigma_{P}$. Nonlinear elastic element deformation occurs. And the corn straw is characterized by viscoelastic deformation, and the deformation equations can be expressed as in the following equation:

$$
\sigma=m \cdot\left(\varepsilon-\varepsilon_{p}\right)^{3}+n \cdot\left(\varepsilon-\varepsilon_{p}\right)^{2}+E \cdot\left(\varepsilon-\varepsilon_{p}\right)+\sigma_{p} .
$$

From the aforementioned, the following equation can be obtained:

$$
\begin{aligned}
& \sigma=E \cdot \varepsilon, \quad \sigma<\sigma_{p}, \\
& \sigma=m \cdot\left(\varepsilon-\varepsilon_{p}\right)^{3}+n \cdot\left(\varepsilon-\varepsilon_{p}\right)^{2}+E \cdot\left(\varepsilon-\varepsilon_{p}\right)+\sigma_{p}, \\
& \sigma \gg \sigma_{p} .
\end{aligned}
$$

3.2. Parameters. To characterise model of (5), three parameters $(E, m, n)$ are needed. The parameters of the model are 


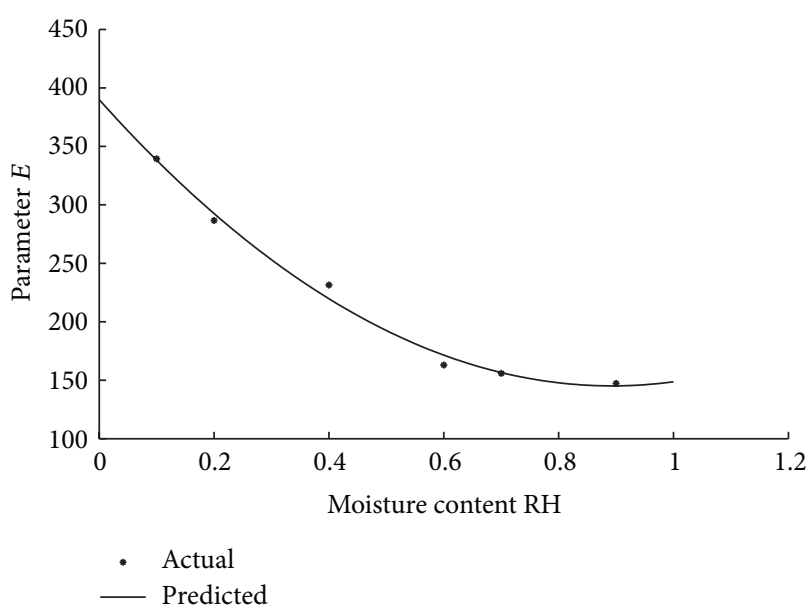

(a)

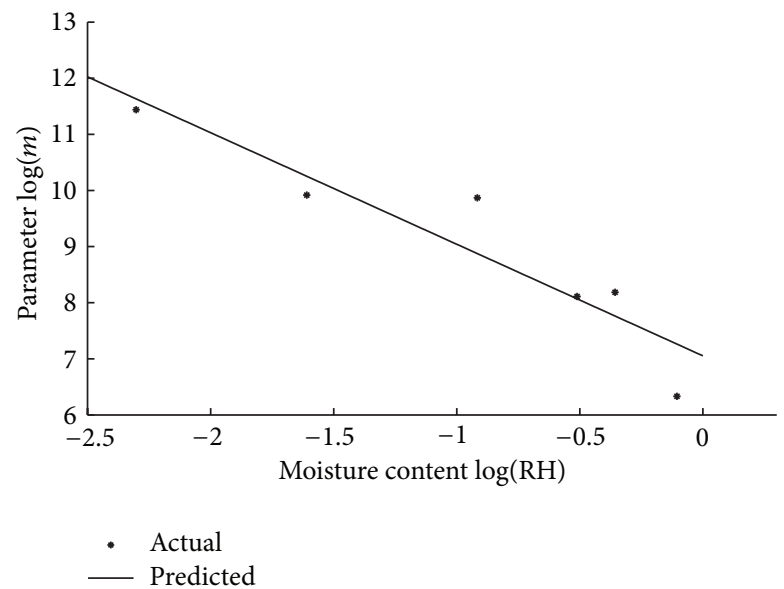

(b)

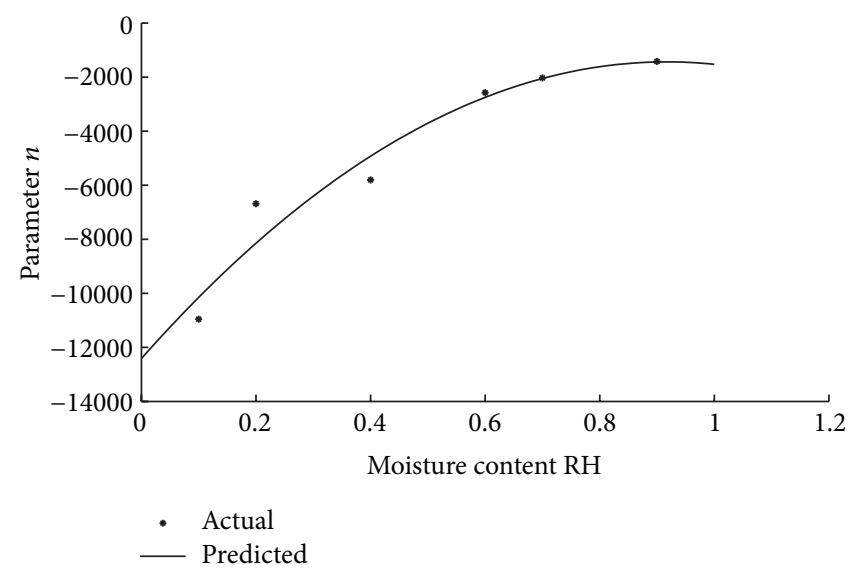

(c)

FIGURE 3: Fitting figure of parameters and moisture content.

determined according to the features of three-point bending test curve and the model.

According to the standard of GB/T 1040.1 2006, the interval can be determined 0.0005 to 0.0025 . Dongmei and Zhiwei suggested that the elastic range is limited to strain between 0.0008 and 0.0015 through experiments research [11]. However, this subjective judgment makes the data inaccurate. The linear elastic of corn straw in different moisture content interval can be determined through differentialcurve variational method [12-14].

According to the yield point $Q$ of corn straw, the parameters $m$ and $n$ can be determined as

$$
\sigma=\sigma_{y},\left.\quad \frac{d \sigma}{d \varepsilon}\right|_{\varepsilon=\varepsilon_{y}}=0 .
$$

$\sigma_{y}, \varepsilon_{y}$ are yield stress and yield strain of $Q$.

Parameters of corn straw's stress-strain model can be obtained according to the previous formulas.

Experiment and theory simulation figure of stress-strain are shown (Figure 2).

Results show that the theoretical model and the test results of stress-strain curves are very fit before the yield stress. Parameters $E, m$, and $n$ are closely related to the moisture content. Parameters $E$ and $m$ are in negative correlation with moisture content, and they decrease with the increase of moisture content. Parameter $n$ is positively related to moisture content. The study of corn straw harvest can provide the reference for the design of crushing equipment.

The regression equation of moisture content and three parameters $E, m, n$ can be fitted, respectively. The corresponding equations are shown as (7) and the curses are shown as Figure 3. Consider

$$
\begin{gathered}
E=307.20 \mathrm{RH}^{2}-548.42 \mathrm{RH}+389.93, \\
\log (m)=-1.99 \log (\mathrm{RH})+7.05, \\
n=-13049 \mathrm{RH}^{2}+23936 \mathrm{RH}-12413 .
\end{gathered}
$$

\section{Energy Absorption Performance of Corn Straw}

From stress-strain curve of corn straw in different moisture contents, when the straw bending strain reaches 0.2 , stress almost would not decrease with the increase of strain. Energy absorption performance is studied with Matlab. When 


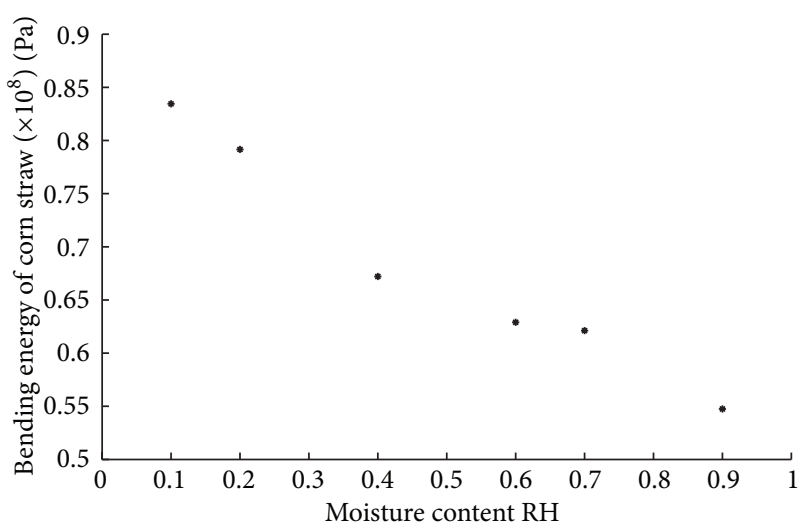

FIGURE 4: The total strain energy absorption in different moisture contents.

the strain reaches 0.2 , the total strain energy absorption in different moisture contents is shown in Figure 4.

With the increase of the moisture content, the total energy absorption of the corn straw is reduced and presents a linear relationship. This is due to the higher moisture content of corn straw, the fiber being more soft, and the stiffness being lower, and the easier it is to bend, and the less energy it needs.

\section{Conclusion}

This paper, based on the three-point bending test of the corn straw of the different moisture content, builds stressstrain models, respectively, and gets all parameters according to the test. The correlation between all parameters and moisture contents was fitted through the software of Matlab. Finally, energy absorption behavior of the straw is briefly analyzed when the strain is 0.2. Corn straw, as a typical biomass material, has large discrete mechanical properties. The mechanical properties of the corn straw are not only related with the moisture content, but also with the origin of the corn stalk, variety, section position, and shape of the samples. The relevant mechanics research of the corn straw, based on the fracture and crush due to the other factors, also needs further study.

\section{Authors' Contribution}

Jiang Huan-Xin contributed equally to this paper as cofirst author.

\section{Acknowledgments}

This work was supported by the National Natural Science Foundation of China (Grant no. 51205167), Research Fund of Young Scholars for the Doctoral Program of Higher Education of China (Grant no. 20120093120014), and Fundamental Research Funds for the Central Universities (Grant no. JUSRP51302A).

\section{References}

[1] L. Ya, "Treatment and comprehensive utilization of crop straw," Liaoning Agricultural Sciences, vol. 1, pp. 18-23, 2003.
2] Z. Lingfeng, D. Lei, L. Xinbao, L. Guoting, and Z. Jie, "Kinetics of preparing methanol with corn stover syngas," Transactions of the Chinese Society of Agricultural Engineering, vol. 24, no. 6, pp. 36-40, 2008.

[3] H. Lujia, Y. Qiaojuan, L. Xiangyang, and H. Jinyou, "Straw resources and their utilization in China," Transactions of the Chinese Society of Agricultural Engineering, vol. 18, no. 3, pp. 8791, 2002.

[4] C. Igathinathane, A. R. Womac, and S. Sokhansanj, "Corn stalk orientation effect on mechanical cutting," Biosystems Engineering, vol. 107, no. 2, pp. 97-106, 2010.

[5] G. Mengxiang, G. Kangquan, Y. Pingzhong, and L. Xingshu, "Study on mechanical properties of cornstalk," Transactions of the Chinese Society of Agricultural Machinery, vol. 34, no. 7, pp. 47-52, 2003.

[6] Y. Zhihua, F. Baoping, Z. Anqing, and L. Aiqin, "Dynamic analysis and comprehensive evaluation of crop-stem lodging resistance," Transactions of the Chinese Society of Agricultural Engineering, vol. 18, no. 6, pp. 30-31, 2002.

[7] C. T. Wright, P. A. Pryfogle, N. A. Stevens, E. D. Steffler, J. R. Hess, and T. H. Ulrich, "Biomechanics of wheat/barley straw and corn stover," Applied Biochemistry and Biotechnology A, vol. 121, no. 1-3, pp. 5-19, 2005.

[8] L. Ruxin, G. Aijun, Z. He, B. Wei, and F. Xiuwen, "Test of rheological behavior on corn stalk volume pressure," Transactions of the Chinese Society of Agricultural Engineering, vol. 18, pp. 3035, 2012.

[9] L. Pena, I. Gonzalez, R. J. Bayer, N. E. E. Mansouri L, and F. Vilaseca, "Mechanical behavior of thermo-mechanical corn stalk fibers in high density polyethylene composites," Journal of Biobased Materials and Bioenergy, vol. 6, no. 4, pp. 463-469, 2012.

[10] P. S. Chattopadhyay and K. P. Pandey, "Mechanical properties of sorghum stalk in relation to quasi-static deformation," Journal of Agricultural Engineering Research, vol. 73, no. 2, pp. 199-206, 1997.

[11] W. Dongmei and W. Zhiwei, "Research progress on buffer performance of paper structural packaging materials," Material Review, vol. 06, pp. 43-46, 2007.

[12] E. yuping, Influence of Relative Humidity and Strain Rate on the Energy Absorption Properties of Paper-Based Cushioning Materials, Jaingnan University, WuXi, China, 2010.

[13] L. qingzhi, Studies on the Molecular Simulation of Diffusion Process in Reverse Osmosis Membrane and Water Solution[D] [Doctoral thesis], Ocean University of China, Qingdao, China, 2007.

[14] J. Wang, "He's max-min approach for coupled cubic nonlinear equations arising in packaging system," Mathematical Problems in Engineering, vol. 2013, Article ID 382509, 4 pages, 2013. 


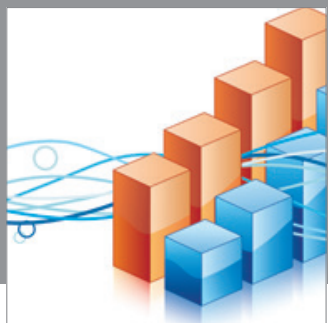

Advances in

Operations Research

mansans

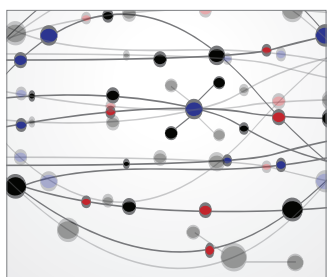

The Scientific World Journal
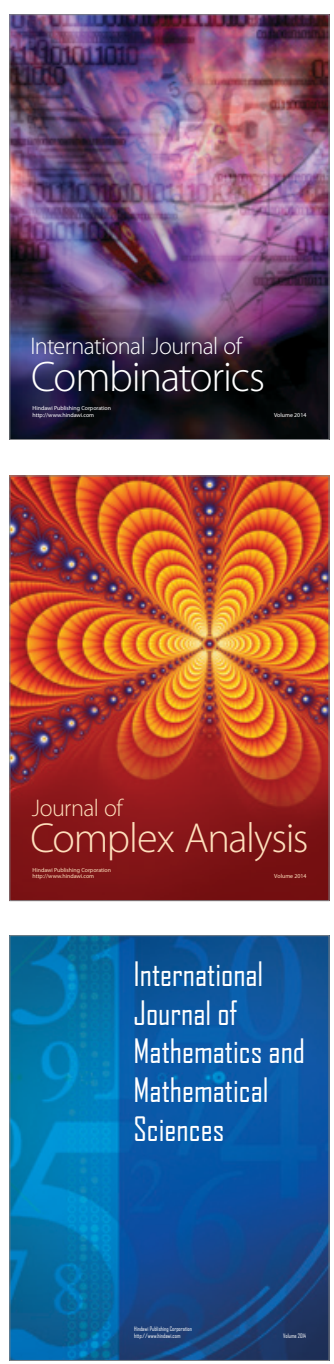
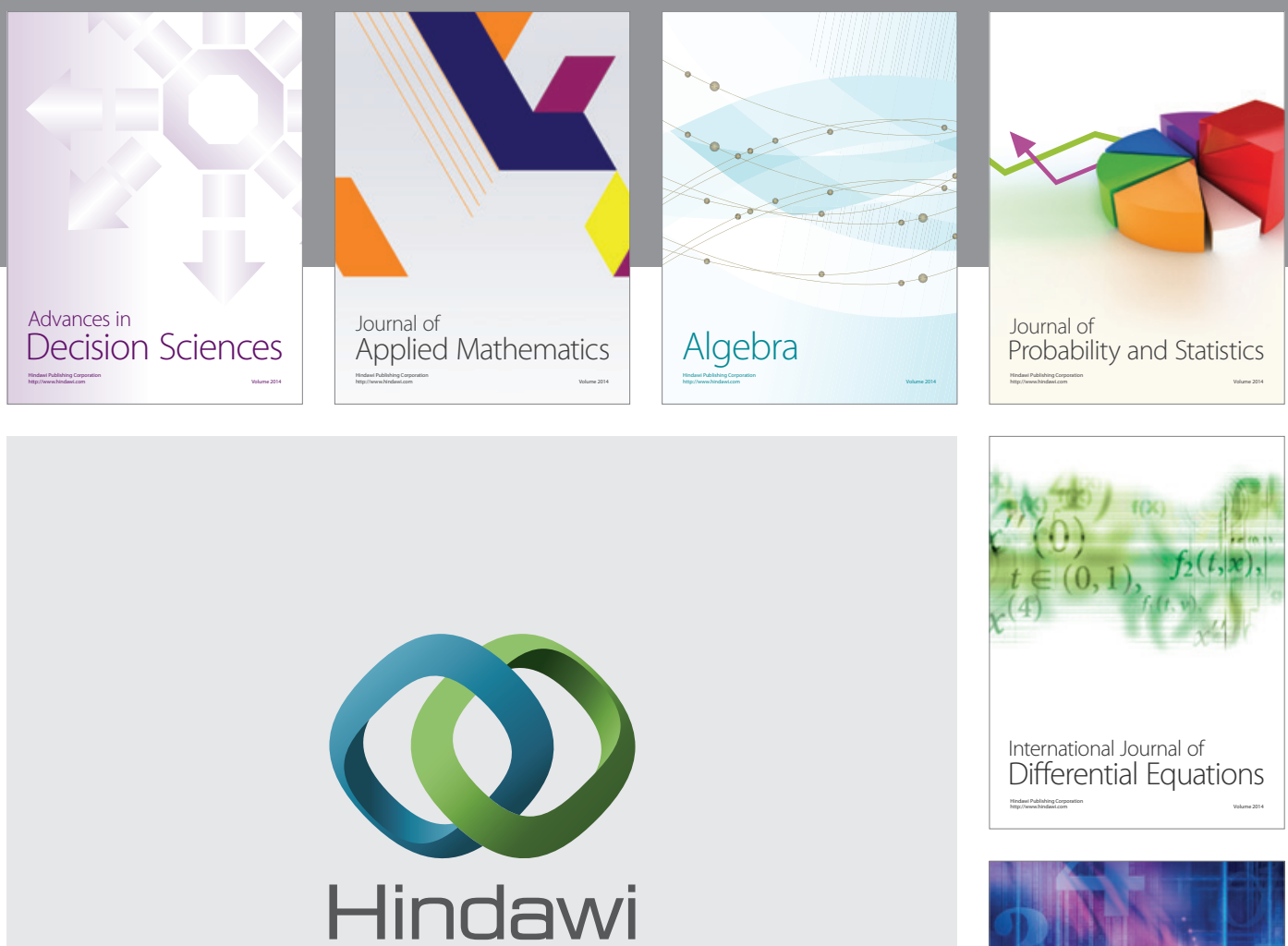

Submit your manuscripts at http://www.hindawi.com
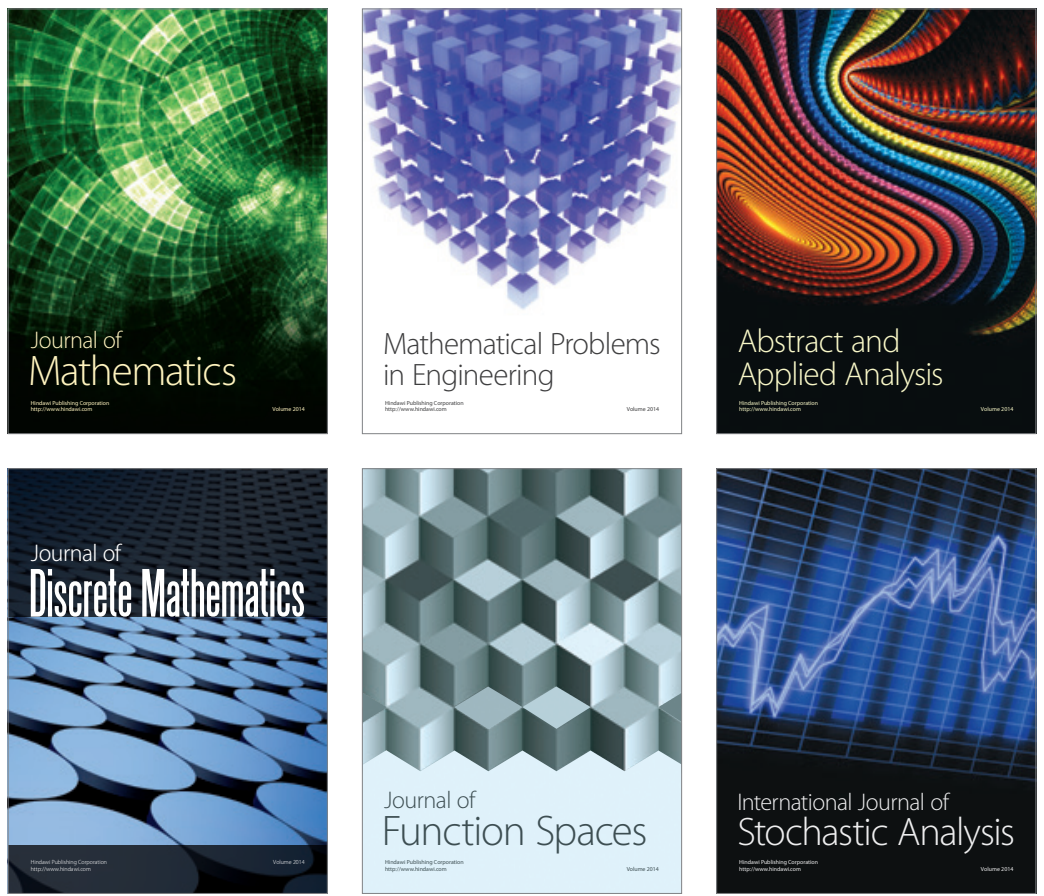

Journal of

Function Spaces

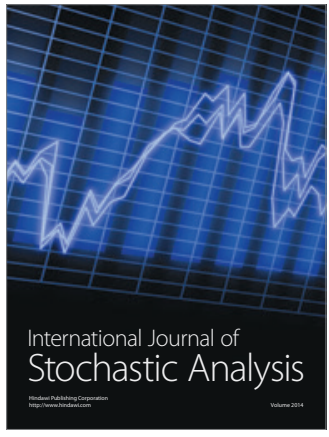

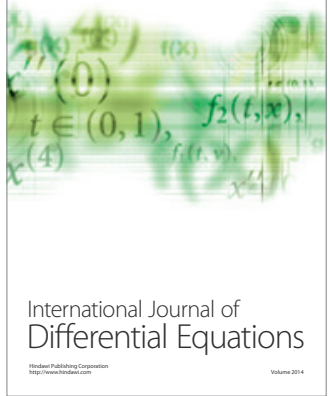
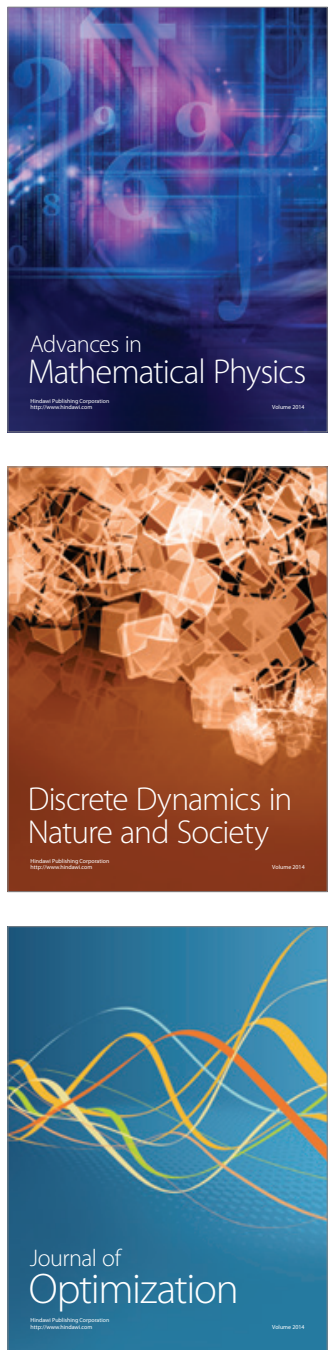